\title{
Genetic Diversity, Epigenetic Reprogramming and Environmental Factors: Leading Directions in the Study of the Complex Human Diseases
}

\author{
Marietta Eliseyeva, $\mathrm{PhD}, \mathrm{ScD}$ \\ International Medical Research and Development Corporation, NY, USA
}

\begin{abstract}
The article discusses the main issues of the complex interactions between genetic, epigenetic and environmental factors in the development of the complex human diseases.(International Journal of Biomedicine. 2017;7(4):269-275.)
\end{abstract}

Key Words: genetic diversity $\bullet$ epigenetic reprogramming $\bullet$ environmental factors $\bullet$ complex human diseases

Complex human diseases originate from Paleolithic caves, where Homo sapiens (HS) started. The oldest human alleles originated in Africa, in parallel with the development of our species, millions of years before people first migrated out of Africa 50,000 to 60,000 years ago. ${ }^{(1,2)}$ These ancient polymorphisms are shared by all human populations; they account for approximately $90 \%$ of human variation and reflect the evolution of the human genome. ${ }^{(3)}$ The genetic diversity of man dates back to an ancestral African population that lived about 200,000 years ago. In the course of their many thousands of years of development, modern humans have faced the global challenges of the external environment. The colonization of other continents and other climatic zones, which started about 70-40 thousand years ago and lasted for 40-45 thousand years with the waves of hybridization (interbreeding of HS with the Neanderthal man and Denisovan man), was accompanied by global environmental challenges and required adaptation to new habitat conditions.

The Neolithic revolution (the transition from the appropriative economy to a producing economy, 12,0009,000 years ago) with the development of agriculture, cultural farming and cattle breeding, led to a rapid expansion of the population and a drastic change in diet, necessitating changes to adapt to the changed structure of nutrition and metabolism. Therefore, some genetic changes are associated with differences in types of nutrition. The most known among them is hypolactasia-lactose intolerance. Lack of lactase in adults is the initial ancestral sign for HS. However, most adult Europeans produce lactase and can drink milk without harm to health. These people are carriers of a mutation in the DNA region that regulates the synthesis of lactase. The mutation spread after the appearance of dairy cattle breeding about
9-10 thousand years ago and is found mainly among European peoples. The traditional diet acts as a selection factor and leads to a change in the frequencies of alleles and the spread in the population of genetic variants that are most adaptive with this diet. In another example, the encounter between the ancient civilization and Scythians in the Northern Black Sea region in the 4th century BC, was accompanied by "global food stress." Nutrition conflict gave rise to catastrophic consequences. The first wave of settler Greeks died from the cold and unusual food 5-10 years after relocation. At the genetic level, a conflict of enzymes began. For example, Greek wine became a catastrophe for nomads due to the lack of the enzyme alcohol dehydrogenase. "Drunk as a Scythian" (Herodotus: The History). Biologically, HS and their immediate ancestors for hundreds of thousands of years adapted to the lifestyle of hunter-gatherers. Then came the transition from gathering to agriculture, with its accompanying changes in diet and lifestyle, which continued for tens and hundreds of generations.

Adaptation of the population to dietary factors and lifestyle is accompanied by genetic changes with an increase in the frequency of adaptive alleles in the population. However, the human genome, as a relatively slowly evolving system, is not able to change under the pressure of environmental factors in a small number of generations and quickly respond to the challenges of the environment.

With the development of the producing economy, along with infectious diseases, many common diseases that rarely occurred in ancient hunter-gatherers, or were in general unknown, appeared. For example, the low-cholesterol diet of hunter-gatherers made them adaptive for the ability to intensively absorb cholesterol, which under the new conditions became a risk factor for atherosclerosis. Epochal 
studies conducted 100 years ago in Egypt by Sir Mark Armond Raffer, allowed the signs of atherosclerosis to be revealed histologically in the aorta and other large arteries of numerous Egyptian mummies, that were 3,000 years old. ${ }^{(4)}$ The presence of the signs of atherosclerosis in the aorta and other large arteries in 76 Egyptian mummies was confirmed by wholebody CT scanning study by AH Allam and colleagues. ${ }^{(5)}$

Having passed the line of modern chronology (A.D.), mankind again began to move around the planet: the Great Migration of Peoples (3rd-7th centuries), with mass migration of the population, habitat change, assimilation of peoples, the destruction of some and the formation of new ethnic groups. Great geographical discoveries (15th-16th centuries) and the "Columbus exchange" (plants, animals, food, peoples, and infectious diseases moving around the planet) are considered by scientists as a stage of the "First Globalization." Together with migrations, infections such as smallpox, leprosy, plague, tuberculosis, malaria, and syphilis were rampant on the planet. Epidemics - a characteristic sign of the Middle Ages - were the result of the growth of cities, terrible famine, climate change, unsanitary conditions, mass migration of a large number of people, and crusades.

The first pandemic of the plague (Justinian Plague), which was preceded by the pandemic of leprosy and smallpox, which originated in the Eastern Roman Empire in the 6th century and covered almost the entire territory of the civilized world, killed more than 100 million people for several years. The second pandemic, widely known as the Black Death or the Great Plague, originated in China in 1334 and spread along the great trade routes to Constantinople and then to Europe, where it claimed an estimated $60 \%$ of the European population. ${ }^{(6)}$

Epidemics made the problem of resistance to infections urgent. Epidemics, often associated with wars, can change the frequencies of alleles throughout the lifespan of one generation due to a sharp decline in the population.

The first studied example of resistance is found in the spread of sickle cell anemia, a hereditary disease in the tropical and subtropical zones caused by a mutation in the hemoglobin gene. Mutation carriers were resistant to malaria. Researchers found that in the areas with a high incidence of malaria, the heterozygous condition is most "advantageous," since homozygous carriers of mutant hemoglobin die from anemia, homozygous carriers of the normal gene are affected by malaria, and in heterozygous carriers anemia appears in a mild form, but these carriers are protected from malaria.

A very interesting story of positive selection in the human genome is the 32-bp deletion in the chemokine receptor CCR5, a variant that confers resistance to AIDS. C-C chemokine receptor type 5 (CCR5) is a type of chemokine defined as small proteins having diverse functions that include immune surveillance and immune cell recruitment. In 1996, it was discovered that CCR5 behaves as a co-receptor for entry of HIV into cells. ${ }^{(7)}$ CCR5 receptors are not expressed on the cell surfaces in homozygous individuals having the CCR5- $\triangle 32$ variant due to an incomplete protein providing high level protection against HIV infection. ${ }^{(8)}$ Studies have found that although heterozygous individuals carrying the CCR5- $\triangle 32$ allele can be infected by HIV, the disease progression rate is slower in these people. ${ }^{(9)}$ About $1 \%$ of Caucasian people have inherited two copies of CCR5- $\triangle 32$ genes leading to virtual immunity to HIV infection. On the other hand, $20 \%$ of Caucasians carry only one copy of the CCR5- $\triangle 32$ allele, which gives some protection against infection, thus making the disease less severe when infection occurs. ${ }^{(10)}$ This variant was postulated to be a relatively recent response to plague or smallpox. New research shows that the frequency of CCR5Delta32 in Bronze Age samples is similar to that seen today, pushing the observed age of the allele back to at least 3,000 and possibly 5,000 years ago. ${ }^{(11)}$

A powerful global challenge for modern humans was the Great Industrial Revolution (the period from the end of the 18 th century to the beginning of the 20th century) with the development of industry, urbanization, and pollution of the environment with a large number of new chemicals that did not exist in nature before. The tremendous leap in the development of science, technology, and medical care have increased the human life expectancy with a shift in the vector of morbidity. Information globalization (from the 20th century to the present), adopting the baton of the Great Industrial Revolution, defined a new level in the development of civilization, with fundamentally new opportunities and previously unknown problems of human development, with changing traditional stereotypes of behavior and lifestyle, and with the changing population age structure and signs of a demographic revolution. The rapidity of change and the contraction of historical time - the basic characteristics of the modern period of globalization-have become a new and powerful challenge for modern HS.

Exponential population growth, fueled by the development of agriculture in the past 10,000 years and of urbanization in the past 700 years, has resulted in a vast number of new alleles. ${ }^{(3)}$ Collectively, these alleles have generated an immense degree of genetic variation. Given the size of the present-day human population, every point mutation compatible with life is likely present in someone, somewhere. ${ }^{(3)}$

\section{Genetic variations as disease markers}

Human genetic variations - the differences in DNA sequence within the genome of individuals in populationscan take many forms, including single nucleotide changes or substitutions, tandem repeats, insertions and deletions (indels), additions or deletions that change the copies number of a larger segment of DNA sequence (that is, copy number variations $(\mathrm{CNVs}))$, other chromosomal rearrangements such as inversions and translocations (copy neutral variations), loss of heterozygosity (LOH), copy neutral LOH (acquired uniparental disomy). ${ }^{(12)}$

Single nucleotide polymorphisms (SNPs) are the most abundant type of genetic variation in the human genome. This is approximately equivalent to 3 million SNPs being carried by each individual genome. Therefore, the DNA sequence of any two genomes is estimated to be about $99.9 \%$ identical, and the $0.1 \%$ genetic variations that are mainly comprised of SNPs are believed to be responsible for the phenotypic differences, such as physical traits (for example, height, and hair and eye colors), disease susceptibility, and drug responses, among 
individuals in populations. $^{(12)}$

The completion of the Human Genome Project is a major scientific development in human genomics and biomedical sciences. The reference DNA sequence has provided the basis for studying genetic variations in the human genome among individuals in populations. Information on the complete sequence of the human genome is freely available (http://genome.ucsc. edu; http://www.ensemble.org; http:/www.ncbi.nlm.nih.Gov/ genome/quide/human). Currently, after the completion of the Human Genome Project, more than 17 million SNPs in human genome have been documented in the dbSNP.

Genome-wide association studies (GWAS) designed to discover SNPs that are associated with a complex trait with the genotyped SNPs have reported thousands of SNPs that are robustly associated with one or more complex traits, including quantitative traits and common diseases. ${ }^{(13,14)}$ Typically, the associated SNPs in total only explain a small proportion of the genetic variation in the population, and this observation has led to the perceived problem of "missing heritability."(15-17) Most of the risk alleles that have been identified by GWAS are common (allele frequency $>5 \%$ ) and confer small effect sizes (odds ratio $<1.5) .{ }^{(18,19)}$ The vast majority of such variants have no established biological relevance to disease or clinical utility for prognosis or treatment. ${ }^{(3)}$ For example, a recently published 12-year followup study of cardiovascular disease (CVD) in more than 19,000 women found that the 101 SNPs identified by GWAS as risk variants for CVD did not predict cardiovascular outcomes. ${ }^{(20)}$ However, there are more examples of how common variants make a major contribution to disease. Sickle cell anemia and the thalassemias are caused by multiple mutations in hemoglobin genes that persist at polymorphic frequencies in malarial endemic regions worldwide. ${ }^{(21)}$ Autoimmune conditions, such as systemic lupus erythematosis, multiple sclerosis, type I diabetes, and rheumatoid arthritis, are strongly influenced by common polymorphic variations at the MHC loci. Alzheimer's disease is strongly influenced by an allele of APOE4 that occurs at polymorphic frequencies in most populations. ${ }^{(23)}$ Lactose intolerance (or lactase persistence) is caused by the effect of any one of several different alleles in noncoding enhancers of the lactase promoter; different regulatory alleles are common in different populations. ${ }^{(24)}$

The recognition that rare alleles are important contributors to common complex human diseases is a major paradigm shift in human genetics. ${ }^{(3)}$ For example, Liddle's syndrome - a very rare form of hypertension ${ }^{(25)}$ influenced by rare genetic variations - and familial breast cancer induced by BRCA1 and BRCA2 mutations implicate multiple, highly penetrant, yet very rare, variations and yet both hypertension and breast cancer have more common forms for which GWA studies and related strategies have been, and should be, pursued.

The genetic architecture of complex diseases remains elusive. How much each type of genetic variation contributes to inherited risk and the relative proportion of rare versus common variants is unclear. ${ }^{(12)}$ A good source to impute missing genotypes for previous GWAS data became the 1000 Genomes Project, which created the largest public catalogue of human variation and genotype data. The goal of the 1000 Genomes
Project was to find most genetic variants with frequencies of at least $1 \%$ in the populations studied. Data from the 1000 Genomes Project is available to the worldwide scientific community through freely accessible public databases.

\section{Epigenetic Reprogramming}

The ultimate goal of gene discovery in a complex disease is to identify and characterize biological pathways and processes critical to the disorder. Key pathways may be disrupted via many different causes - genetic, epigenetic, and environmental. ${ }^{(3)}$ The traditional view that interactions between genes and the environment control disease susceptibility can now be expanded to include epigenetic reprogramming as a key determinant of the origins of human disease. ${ }^{(26)}$ Currently, epigenetics is defined as heritable changes in gene expression that do not alter DNA sequence but are mitotically and transgenerationally inheritable.

The term "epigenetic" was coined by Waddington ${ }^{(27)}$ to refer to heritable alterations in gene expression that are not due to changes in DNA sequence. Epigenetic modification, such as DNA methylation and histone modification, alter DNA accessibility and chromatin structure, thereby regulating patterns of gene expression. Molecular mechanisms of epigenetic reprogramming include DNA methylation, histone modification, non-coding RNA, nucleosome positioning and many others. These molecular changes are able to maintain in various tissues and organs those features of gene expression that give them all the necessary properties and distinguish certain tissues and organs from others. The entire sum of epigenetic transformations is understood as an epigenom. An epigenom can be considered as a connecting link between the static genome and the constantly changing environment. ${ }^{(28,29)}$ The activity of the epigenome defines the programs of gene expression that act in certain types of cells at the right time. It can be said that the phenotype is the result of a cooperative interaction of the genotype (a specific sequence of DNA) and the epigenotype. Thus, epigenetic reprogramming is the process by which an organism's genotype interacts with the environment to produce its phenotype and provides a framework for explaining individual variations and the uniqueness of cells, tissues, or organs despite identical genetic information. ${ }^{(26)}$

Given its central importance in non-genomic inheritance and earlier discovery, DNA methylation has been named the "prima donna" of epigenetics. ${ }^{(30)}$ DNA methylation is a heritable epigenetic mark involving the covalent transfer of a methyl group to the $\mathrm{C}-5$ position of the cytosine ring of DNA by DNA methyltransferases. ${ }^{(31)}$

This chemical modification occurs predominantly on $\mathrm{CG}$ dinucleotides in mammalian genomes. However, recent studies have revealed that non- $\mathrm{CG}$ methylation $(\mathrm{mCH})$ is abundant and nonrandomly distributed in the genomes of pluripotent cells (embryonic stem cells) and brain cells, and is present at lower levels in many other human cells and tissues. ${ }^{(32)}$ M.D. Schultz with colleagues ${ }^{(33)}$ identified widespread tissue-specific differential $\mathrm{CG}$ methylation (mCG), partially methylated domains, allele-specific methylation and transcription, and the unexpected presence of $\mathrm{mCH}$ in almost all human tissues. 
DNA methylation is typically considered a potentially enduring epigenetic modification (particularly among postmitotic cells). In contrast, posttranslational modifications to the N-terminus tails of histone proteins are highly varied and dynamic and include acetylation, methylation, phosphorylation, and ubiquitination. These epigenetic processes are not independent (i.e., DNA methylation can influence histone modification and vice versa) and collectively influence the accessibility of DNA to transcription factors and RNA polymerase. DNA methylation is typically associated with reduced transcription, and histone acetylation is typically associated with increased gene expression. ${ }^{(34-36)}$

Most DNA methylation is essential for normal development, and it plays a very important role in a number of key processes, including genomic imprinting, X-chromosome inactivation, and suppression of repetitive element transcription and transposition. ${ }^{(37)}$ DNA methylation can be affected by both inherited DNA sequence variation and a broad range of environmental factors, such as nutrition, exposure to toxic pollutants and social environment. ${ }^{(38-41)}$

The state of genome instability in connection with the violation of DNA methylation processes appears to be the fundamental basis for the manifestation and/or maintenance of the pathological process in carcinogenesis, atherosclerosis, autoimmune process. ${ }^{(42-45)}$

The phenomenon of total hypomethylation, which is the most important indicator of genome instability, is defined quite clearly in three acute conditions of the organism: at the very beginning of embryonic development, at the final stages of ontogeny of the organism in the process of its aging and, finally, in the process of malignant transformation. Generally, during the aging process, global hypomethylation of DNA occurs in a repetitive sequence pattern that may promote genomic instability. ${ }^{(46)}$ Not only is aging correlated with hypomethylation of proto-oncogenes, but also with hypermethylation of tumor suppressor genes, potentially leading to increased risk of cancer and other diseases. ${ }^{(47)}$

Epigenetic changes in disease are not always focal, but can be global and encompass large chromosomal regions.(48) For example, the aberrant expression of micro RNAs has been linked to various age-related diseases, such as Alzheimer's disease, cardiac disease and many cancers, including leukemia and lymphoma. ${ }^{(49-53)}$

Hypomethylation in atherosclerosis, as well as in cancer, contributes to the pathogenesis of the disease, inducing chromosomal instability, affecting such specific genes related to the development of the disease as the genes of 15-lipoxygenase and extracellular superoxide dismutase. ${ }^{(54)}$ Atherosclerosis is also marked by the hypermethylation of individual genes. This concerns such an important gene for the development of atherosclerosis and aging in general, as the estrogen receptor- $\alpha$ gene on smooth muscle cells. ${ }^{(55)}$ It is the presence of these receptors on cells that allows the antiproliferative effect of estrogens in smooth muscle cells (SMCs), thereby providing cardiovascular protection; suppressing the expression of the receptor gene will promote the induction of the proliferation of SMCs, thereby contributing to the development of atherosclerosis. ${ }^{(56)}$ In addition, the activated estrogen receptors increase the expression/activity of NO synthase, and hence the production of NO itself, which also has the ability to inhibit the proliferation of SMCs in the vessels. ${ }^{(57)}$ Recent studies have shown that differences in DNA methylation exist between major ethnic groups, ${ }^{(58-61)}$ highlighting the potential contribution of epigenetic modifications to human phenotypic variation.

Maud Fagny and colleagues ${ }^{(61)}$ have found that the current habitat and historical lifestyle of a population have similarly critical impacts on the methylome, but the biological functions affected differ strongly. Specifically, the methylation variation associated with recent changes in habitat mostly concerns immune and cellular functions, whereas the variation associated with historical lifestyle affects developmental processes. Furthermore, methylation variation - particularly that correlated with historical lifestyle — shows strong associations with nearby genetic variants that, moreover, are enriched in signals of natural selection. Maud Fagny and colleagues have suggested that populations can initially respond to environmental challenges via epigenetic changes, uncoupled from variation in the DNA sequence, with the adaptive phenotype increasingly being achieved via genetic changes as time passes. ${ }^{(61)}$

It has also been suggested that epigenetic changes may account for the missing heritability determinants of complex diseases, such as atherosclerosis, hypertension, metabolic syndrome, and diabetes. ${ }^{(42-45,62)}$

Hyperhomocysteinemia in atherosclerosis is perhaps one of the mechanisms of the phenomenon of total DNA hypomethylation, characterizing, apparently, both the onset and progression of the disease. Homocysteine (Hcy) is biochemically linked to the principal epigenetic tag found in DNA. Hcy plays a crucial role in methyl-donor biosynthesis. ${ }^{(63)}$ The methyl-group responsible for DNA and histone methylation originates from S-adenosyl methionine (AdoMet), via Met biosynthesis through folate-dependent or -independent pathways of Hcy remethylation. Following the transfer of the methyl group, AdoMet is converted into S-adenosyl homocysteine (AdoHcy), which inhibits the majority of AdoMet-dependent methyltransferases. If Hcy accumulates, AdoHcy will accumulate as well, potentially inhibiting transmethylation reactions. Thus, increased Hcy may be regarded as a global DNA hypomethylation effector via AdoHcy accumulation. Mechanisms of HCy-dependent accumulation of AdoHcy are highlighted in a review by Diane E. Handy. ${ }^{(62)}$ The inverse relationship between Hcy plasma concentrations and DNA methylation patterns has been confirmed in many other reports. ${ }^{(64-67)}$ Several studies support the concept that DNA hypomethylation may be responsible, in part, for vascular complications associated with increased circulating levels of Hcy. ${ }^{(68-73)}$

Growing evidence suggests that chromatin factors are involved in the incidence of T2DM and may mediate the complex interaction between genetic variants, environment, and gene expression. ${ }^{(74)}$ Barrès et al. ${ }^{(75)}$ identified $\mathrm{mCH}$ as one of the critical factors involved in diabetes. They examined the methylation patterns in muscle tissue from a cohort of T2DM, impaired glucose-tolerant, and normal glucose-tolerant individuals. They discovered that the T2DM and impaired glucose-tolerant subjects had significantly higher $\mathrm{mCH}$ in the 
promoter of the PGC-1 $\alpha$ gene compared with normal glucosetolerant subjects, whereas the number of CG sites was limited in the promoter regions and their methylation states were not significantly altered. Barrès et al. ${ }^{(75)}$ found that in human primary myocytes, the $\mathrm{mCH}$ in the $\mathrm{PGC}-1 \alpha$ promoter can be induced by a high concentration of free fatty acids, such as palmitate and oleate or TNF- $\alpha$, all of which were present at high levels in diabetic individuals. PGC- $1 \alpha$ is a critical gene involved in the regulation of mitochondria biogenesis. ${ }^{(76)}$ The $\mathrm{mCH}$ of its promoter was accompanied by lower transcription and a dramatic reduction of mitochondrial DNA content. Furthermore, several recent studies have begun to demonstrate the association between $\mathrm{mCH}$ and Rett syndrome. ${ }^{\text {(77-79) }}$

During the course of human life, there is constant interaction between the external and internal environmentsinteraction that is required for normal development and health maintenance. Exposure to pharmaceutical and toxic chemicals, diet, stress, lifestyle choices, and other environmental factors may result in conflict with the programmed adaptive changes made during early development, and explain the alarming increases in some diseases. ${ }^{(26,48)}$ The plasticity of certain epigenetic modifications can be followed throughout development and differentiation and in response to environmental stimuli. It seems possible that such epigenetic modifications may be amenable to pharmacological interventions. ${ }^{(62)}$ Advances in epigenetic technology may soon allow repair of defective epigenetic modifications by a variety of therapeutics. ${ }^{(48)}$ For example, the drug azacitidine, the first FDA-approved epigenomic drug, treats leukemia by reactivating tumor suppressor genes, and similar drugs are now in development. ${ }^{(80,81)}$

Thus, despite the risk presented by inherited genes and mutations, epigenetic factors play a decisive role in the actual development of disease. Investigation of epigenetic profiling can help in determining the risk of developing a specific disease in an individual with a particular type of genotype. Also the same epigenetic profile, along with knowledge of the genomic sequence, can help to determine which medications or alternative medicine approaches would be effective in preventing or curing a particular disease.

There is a long road between understanding the intimate mechanisms of the genome-epigenome interactions in the development of disease and the targeted therapeutic approaches. The ancient Greeks said that knowledge is the radius of a circle, and ignorance is the circumference of a circle. With the definition of the structure of DNA, the radius of understanding has grown, but at the same time the circumference of the circle has also grown, but we believe that "Viam supervadet vadens" (Lucius Seneca).

\section{References}

1. Cavalli-Sforza LL, Menozzi P, Piazza A. History and Geography of Human Genes. Princeton, NJ: Princeton University Press; 1994.

2. Cavalli-Sforza LL, Feldman MW. The application of molecular genetic approaches to the study of human evolution. Nat Genet. 2003;33 Suppl:266-75.

3. McClellan J, King MC. Genetic heterogeneity in human disease. Cell. 2010;141(2):210-7. doi: 10.1016/j. cell.2010.03.032.

4. Ruffer MA. On arterial lesions found in Egyptian Mummies (1580 BC - 535 AD). J Pathol Bacteriol. 1911;16(4):453-462. 5. Allam AH, Mandour Ali MA, Wann LS, Thompson RC, Sutherland ML, Sutherland JD, et al. Atherosclerosis in ancient and modern Egyptians: the Horus study. Glob Heart. 2014;9(2):197-202. doi: 10.1016/j.gheart.2014.03.2454.

6. Benedictow Ole J. The Black Death 1346-1353: The Complete History. Boydell \& Brewer, Limited; 2008

7. Simon V, Ho DD, Abdool Karim Q. HIV/AIDS epidemiology, pathogenesis, prevention and treatment. Lancet. 2006;368(9534):489-504.

8. Samson M, Libert F, Doranz BJ, Rucker J, Liesnard C, Farber CM, et al. Resistance to HIV-1 infection in caucasian individuals bearing mutant alleles of the CCR-5 chemokine receptor gene. Nature. 1996;382(6593):722-5.

9. Dean M, Jacobson LP, McFarlane G, Margolick JB, Jenkins FJ, Howard OM, et al. Reduced risk of AIDS lymphoma in individuals heterozygous for the CCR5-delta32 mutation. Cancer Res. 1999;59(15):3561-4.

10. Garzino-Demo A. Chemokines and defensins as HIV suppressive factors: an evolving story. Curr Pharm Des. 2007;13(2):163-72.

11. Kaushik M, Chaudhary S, Mahendru M, Kumar M, Kukreti S. Genetic Variations: Heroes or Villains. J Down Syndr Chr Abnorm. 2016;2:2

12. Ku CS, Loy EY, Salim A, Pawitan Y, Chia KS. The discovery of human genetic variations and their use as disease markers: past, present and future. J Hum Genet. 2010 Jul;55(7):403-15. doi:10.1038/jhg.2010.55.

13. Lee SH, Wray NR, Goddard ME, Visscher PM. Estimating missing heritability for disease from genome-wide association studies. Am J Hum Genet. 2011;88(3):294-305. doi: 10.1016/j. ajhg.2011.02.002.

14. Manolio TA. Genomewide association studies and assessment of the risk of disease. $N$ Engl $\mathrm{J}$ Med. 2010;363(2):166-76. doi: 10.1056/NEJMra0905980.

15. Maher B. Personal genomes: The case of the missing heritability. Nature. 2008;456(7218):18-21. doi: 10.1038/456018a.

16. Manolio TA, Collins FS, Cox NJ, Goldstein DB, Hindorff LA, Hunter DJ, et al. Finding the missing heritability of complex diseases. Nature. 2009;461(7265):747-53. doi: 10.1038/nature08494.

17. Edwards MD, Symbor-Nagrabska A, Dollard L, Gifford DK, Fink GR.Interactions between chromosomal and nonchromosomal elements reveal missing heritability.Proc Natl Acad Sci USA. 2014;111(21):7719-22. doi: 10.1073/ pnas. 1407126111.

18. Barr DR, Sherrill ET. Mean and variance of truncated normal distribution. TAS. 1999;53(4):357-361.

19. Dempster ER, Lerner IM. Heritability of Threshold Characters. Genetics.1950;35(2):212-36.

20. Paynter NP, Chasman DI, Paré G, Buring JE, Cook NR, Miletich JP, Ridker PM. Association between a literaturebased genetic risk score and cardiovascular events in women. JAMA. 2010;303(7):631-7. doi: 10.1001/jama.2010.119.

21. Patrinos GP, Kollia P, Papadakis MN. Molecular diagnosis of inherited disorders: lessons from hemoglobinopathies. Hum. Mutat. 2005;26(5):399-412.

22. Fernando MM, Stevens CR, Walsh EC, De-Jager PL, Goyette P, Plenge RM, et al. Defining the role of the MHC 
in autoimmunity: a review and pooled analysis. PLoS Genet. 2008;4(4):e1000024. doi: 10.1371/journal.pgen.1000024.

23. Bird TD. Genetic factors in Alzheimer's disease. N Engl J Med. 2005;352(9):862-4.

24. Tishkoff SA, Reed FA, Ranciaro A, Voight BF, Babbitt CC, Silverman JS, et al. Convergent adaptation of human lactase persistence in Africa and Europe. Nat Genet. 2007;39(1):31-40. 25. Hansson JH, Nelson-Williams C, Suzuki H, Schild L, Shimkets R, Lu Y, et al. Hypertension caused by a truncated epithelial sodium channel gamma subunit: genetic heterogeneity of Liddle syndrome. Nat Genet 1995;11(1):76-82.

26. Tang WY, Ho SM. Epigenetic reprogramming and imprinting in origins of disease. Rev Endocr Metab Disord. 2007;8(2):173-82

27. Waddington $\mathrm{CH}$. The strategy of the genes; a discussion of some aspects of theoretical biology. London: Allen \& Unwin; 1957.

28. Patkin EL, Quinn J. Epigenetic mechanisms of predisposition to complex pathologies of man. Ekol Genetics. 2010;8(4):44-56.

29. Fomchenko EE, Voropaev EV. Biological aspects of DNA methylation. Probl Health Ekol. 2012;(3):55-59.

30. Scarano MI, Strazzullo M, Matarazzo MR, D’Esposito M. DNA methylation 40 years later: Its role in human health and disease. J Cell Physiol. 2005;204(1):21-35.

31. Robertson KD. DNA methylation and human disease. Nat Rev Genet. 2005;6(8):597-610

32. He Y, Ecker JR. Non-CG Methylation in the Human Genome. Annu Rev Genomics Hum Genet. 2015;16:55-77. doi: 10.1146/annurev-genom-090413-025437..

33. Schultz MD, He Y, Whitaker JW, Hariharan M, Mukamel EA, Leung D, Rajagopal N, et al. Human body epigenome maps reveal noncanonical DNA methylation variation. Nature. 2015;523(7559):212-6. doi: 10.1038/nature14465.

34. Gudsnuk K, Champagne FA.Epigenetic influence of stress and the social environment. ILAR J. 2012;53(3-4):27988. doi: 10.1093/ilar.53.3-4.279.

35. Pai AA, Pritchard JK, Gilad Y. The genetic and mechanistic basis for variation in gene regulation. PLoS Genet. 2015;11(1):e1004857. doi: 10.1371/journal.pgen.1004857.

36. Schubeler D. Function and information content of DNA methylation. Nature. 2015 Jan 15;517(7534):321-6. doi: 10.1038/nature14192.

37. Jin B, Li Y, Robertson KD. DNA methylation: superior or subordinate in the epigenetic hierarchy? Genes Cancer. 2011;2(6):607-17. doi: 10.1177/1947601910393957.

38. Kaminsky ZA, Tang T, Wang SC, Ptak C, Oh GH, Wong AH, et al. DNA methylation profiles in monozygotic and dizygotic twins. Nat Genet. 2009;41(2):240-5. doi: 10.1038/ng.286.

39. Feil R, Fraga MF. Epigenetics and the environment: emerging patterns and implications. Nat Rev Genet. 2011;13(2):97-109. doi: 10.1038/nrg3142.

40. Lam LL, Emberly E, Fraser HB, Neumann SM, Chen E, Miller GE, Kobor MS. Factors underlying variable DNA methylation in a human community cohort. Proc Natl Acad Sci USA. 2012;109 Suppl 2:17253-60. doi: 10.1073/pnas.1121249109.

41. Ziller MJ, Gu H, Müller F, Donaghey J, Tsai LT, Kohlbacher O, et al. Charting a dynamic DNA methylation landscape of the human genome. Nature. 2013;500(7463):47781. doi: 10.1038/nature12433.

42. Hiltunen MO, Yla-Herttuala S. DNA methylation, smooth muscle cells, and atherogenesis. Arterioscler Thromb Vasc Biol. 2003;23(10):1750-3.
43. Luczak MW, Jagodzinski PP. The role of DNA methylation in cancer development. Folia Histochem Cytobiol. 2006;44(3):143-54.

44. Kwon NH, Kim JS, Lee JY, Oh MJ, Choi DC. DNA methylation and the expression of IL-4 and IFN-gamma promoter genes in patients with bronchial asthma. J Clin Immunol. 2007;28(2):139-46.

45. Takami N, Osawa K, Miura Y, Komani K, Taniguchi M, Shiraishi M, et al. Hypermethylated promoter region of DR3, the death receptor 3 gene, in rheumatoid arthritis synovial cells. Arthritis Rheum. 2006;54(3):779-87.

46. Heyn H1, Li N, Ferreira HJ, Moran S, Pisano DG, Gomez A, Diez J, et al. Distinct DNA methylomes of newborns and centenarians. Proc NatlAcad Sci USA. 201226;109(26):105227. doi: 10.1073/pnas.1120658109.

47. Coppedè F. Epigenetic biomarkers of colorectal cancer: Focus on DNA methylation. Cancer Lett. 2014;342(2):23847. doi: 10.1016/j.canlet.2011.12.030.

48. Kanherkar RR, Bhatia-Dey N, Csoka AB. Epigenetics across the human lifespan.Front Cell Dev Biol. 2014 Sep 9;2:49. doi: 10.3389/fcell.2014.00049. eCollection 2014.

49. Natarajan AT, Vermeulen S, Darroudi F, Valentine MB, Brent TP, Mitra S, Tano K. Chromosomal localization of human O6-methylguanine-DNA methyltransferase (MGMT) gene by in situ hybridization. Mutagenesis. 1992;7(1):83-5 50. Fabbri M, Croce CM, Calin GA. MicroRNAs in the ontogeny of leukemias and lymphomas. Leuk Lymphoma. 2009; 50(2):160-70. doi: 10.1080/10428190802535114.

51. Cheng Y, Zhang C. MicroRNA-21 in cardiovascular disease. J Cardiovasc Transl Res. 2010;3(3):251-5. doi: 10.1007/s12265-010-9169-7.

52. Montgomery RL, van Rooij E. MicroRNA regulation as a therapeutic strategy for cardiovascular disease. Curr Drug Targets. 2010;11(8):936-42.

53. Provost P. Interpretation and applicability of microRNA data to the context of Alzheimer's and age-related diseases. Aging (Albany NY). 2010;2(3):166-9.

54. Dong C, Yoon W, Goldsmidt-ClermontPJ. DNAmethylation and atherosclerosis. J Nutr. 2002;132(8 Suppl):2406S-2409S 55. Post WS, Goldschmidt-Clermont PJ, Wilhide CC, Heldman AW, Sussman MS, Ouyang P, et al. Methylation of the estrogen receptor gene is associated with aging and atherosclerosis in the cardiovascular system. Cardiovascular Res. 1999;43(4):985-91.

56. Ying AK, Hassanain HH, Roos CM, Smiraglia DJ, Issa JJ, Michler RE, et al. Methylation of the estrogen receptor-alpha gene promoter is selectively increased in proliferating human aortic smooth muscle cells. Cardiovasc Res. 2000;46(1):172-9. 57. Dasgupta C, Chen M, Zhang H, Yang S, Zhang L. Chronic hypoxia during gestation causes epigenetic repression of the estrogen receptor-alpha gene in ovine uterine arteries via heightenedpromotermethylation.Hypertension.2012;60(3):697704. doi: 10.1161/HYPERTENSIONAHA.112.198242.

58. Bell JT, Pai AA, Pickrell JK, Gaffney DJ, Pique-Regi R, Degner JF, et al. DNA methylation patterns associate with genetic and gene expression variation in HapMap cell lines. Genome Biol. 2011;12(1):R10. doi: 10.1186/gb-2011-12-1-r10. 59. Fraser HB, Lam LL, Neumann SM, Kobor MS. Population-specificity of human DNA methylation. Genome Biol. 2012;13(2):R8. doi: 10.1186/gb-2012-13-2-r8.

60. Heyn H, Moran S, Hernando-Herraez I, Sayols S, Gomez A, Sandoval J, et al. DNA methylation contributes to natural human variation. Genome Res. 2013;23(9):1363-72. doi: 
10.1101/gr.154187.112.

61. Fagny M, Patin E, MacIsaac JL, Rotival M, Flutre T, Jones $\mathrm{MJ}$, et al. The epigenomic landscape of African rainforest hunter-gatherers and farmers. Nat Commun. 2015;6:10047. doi: 10.1038/ncomms10047.

62. Handy DE, Castro R, Loscalzo J. Epigenetic modifications: basic mechanisms and role in cardiovascular disease. Circulation. 2011 May 17;123(19):2145-56. doi: 10.1161/ CIRCULATIONAHA.110.956839.

63. Joseph J, Handy DE, Loscalzo J. Quo vadis: whither homocysteine research? Cardiovasc Toxicol. 2009;9(2):5363. doi: 10.1007/s12012-009-9042-6.

64. Yi P, Melnyk S, Pogribna M, Pogribny IP, Hine RJ, James SJ. Increase in plasma homocysteine associated with parallel increases in plasma S-adenosylhomocysteine and lymphocyte DNA hypomethylation. J Biol Chem. 2000; 275(38):29318-23. 65. Stern LL, Mason JB, Selhub J, Choi SW. Genomic DNA hypomethylation, a characteristic of most cancers, is present in peripheral leukocytes of individuals who are homozygous for the C677T polymorphism in the methylenetetrahydrofolate reductase gene. Cancer Epidemiol Biomarkers Prev. 2000; 9(8):849-53.

66. Friso S, Choi SW, Girelli D, Mason JB, Dolnikowski GG, Bagley PJ, et al. A common mutation in the 5,10methylenetetrahydrofolate reductase gene affects genomic DNA methylation through an interaction with folate status. Proc Natl Acad Sci USA. 2002;99(8):5606-11.

67. Castro R, Rivera I, Blom HJ, Jakobs C, Tavares de Almeida I. Homocysteine metabolism, hyperhomocysteinaemia and vascular disease: an overview. J Inherit Metab Dis. 2006;29(1):3-20.

68. Pogribny IP, Beland FA.DNA hypomethylation in the origin and pathogenesis of human diseases. Cell Mol Life Sci. 2009;66(14):2249-61. doi: 10.1007/s00018-009-0015-5.

69. Castro R, Rivera I, Struys EA, Jansen EE, Ravasco P, Camilo $\mathrm{ME}$, etal.IncreasedhomocysteineandS-adenosylhomocysteine concentrations and DNA hypomethylation in vascular disease. Clin Chem. 2003;49(8):1292-6.

70. Werstuck GH, Lentz SR, Dayal S, Hossain GS, Sood SK, Shi YY, et al. Homocysteine-induced endoplasmic reticulum stress causes dysregulation of the cholesterol and triglyceride biosynthetic pathways. J Clin Invest. 2001;107(10):1263-73. 71. Namekata K, Enokido Y, Ishii I, Nagai Y, Harada T, Kimura H. Abnormal lipid metabolism in cystathionine beta-synthase- deficient mice, an animal model for hyperhomocysteinemia. J Biol Chem. 2004;279(51):52961-9.

72. Jacobson TA, Miller M, Schaefer EJ. Hypertriglyceridemia and cardiovascular risk reduction. Clin Ther. 2007;29(5):763-77. 73. Mikael LG, Wang XL, Wu Q, Jiang H, Maclean $\mathrm{KN}$, Rozen R. Hyperhomocysteinemia is associated with hypertriglyceridemia in mice with methylenetetrahydrofolate reductase deficiency. Mol Genet Metab. 2009;98(1-2):187-94. doi: 10.1016/j.ymgme.2009.05.011.

74. Ling C, Groop L. Epigenetics: a molecular link between environmental factors and type 2 diabetes. Diabetes. 2009;58(12):2718-25. doi: 10.2337/db09-1003.

75. Barrès R, Osler ME, Yan J, Rune A, Fritz T, Caidahl K, et al. Non-CpG methylation of the PGC-1alpha promoter through DNMT3B controls mitochondrial density. Cell Metab. 2009;10(3):189-98. doi: 10.1016/j.cmet.2009.07.011.

76. Wu Z, Puigserver P, Andersson U, Zhang C, Adelmant $\mathrm{G}$, Mootha $\mathrm{V}$, et al. Mechanisms controlling mitochondrial biogenesis and respiration through the thermogenic coactivator PGC-1. Cell. 1999;98(1):115-24.

77. Chen L, Chen K, Lavery LA, Baker SA, Shaw CA, Li W, Zoghbi HY. MeCP2 binds to non-CG methylated DNA as neurons mature, influencing transcription and the timing of onset for Rett syndrome.Proc Natl Acad Sci USA. 2015;112(17):5509-14. doi: 10.1073/pnas.1505909112.

78. Gabel HW, Kinde B, Stroud H, Gilbert CS, Harmin DA, Kastan NR, et al. Disruption of DNA-methylationdependent long gene repression in Rett syndrome. Nature. 2015;522(7554):89-93. doi: 10.1038/nature14319.

79. Guo JU, Su Y, Shin JH, Shin J, Li H, Xie B, et al. Distribution, recognition and regulation of non-CpG methylation in the adult mammalian brain. Nat Neurosci. 2014;17(2):215-22. doi: 10.1038/nn.3607.

80. Braiteh F, Soriano AO, Garcia-Manero G, Hong D, Johnson MM, Silva Lde P, et al. Phase I study of epigenetic modulation with 5-azacytidine and valproic acid in patients with advanced cancers. Clin Cancer Res. 2008;14(19):6296301. doi: 10.1158/1078-0432.CCR-08-1247.

81. Raffoux E, Cras A, Recher C, Boëlle PY, de Labarthe A, Turlure $\mathrm{P}$, et al. Phase 2 clinical trial of 5-azacitidine, valproic acid, and all-trans retinoic acid in patients with high-risk acute myeloid leukemia or myelodysplastic syndrome. Oncotarget. 2010;1(1):34-42. 